\title{
LIBERDADE DE EXPRESSÃO E DE INFORMAÇÃO: ANÁLISE DOS SITES DOS PRINCIPAIS PARTIDOS POLÍTICOS BRASILEIROS A PARTIR DA PROPOSTA DE CASS SUNSTEIN NA OBRA "REPUBLIC.COM 2.0"
}

\author{
Rafaela Bolson Dalla Favera \\ Universidade Federal de Santa Maria - UFSM - Brasil \\ Patrícia dos Reis \\ Universidade Federal de Santa Maria - UFSM - Brasil
}

\begin{abstract}
Resumo
O objetivo do presente trabalho é investigar se os principais partidos políticos brasileiros aderem à proposta de Cass Sunstein na obra "Republic.com 2.0". Para tanto, foi utilizado o método de abordagem dedutivo, tendo a pesquisa perpassado pelo estudo da liberdade de expressão e de informação, pela referida obra e, por fim, pelo estudo dos sites dos partidos no Brasil. Já o método de procedimento empregado foi o monográfico, com o objetivo de expor a obra do autor e refletir acerca da sua principal proposta. Além das técnicas de pesquisa bibliográfica e de observação direta, sistemática e não participativa. Concluiu-se que os partidos brasileiros não aderem à proposta de Sunstein, no que diz respeito ao fornecimento de links para outros sites partidários com pontos de vista ou posicionamentos opostos em suas homepages, e que, pelo contrário, adotam a "política do escândalo", algo antidemocrático.
\end{abstract}

Palavras chave: Cass Sunstein; Direito de acesso à informação; Liberdade de expressão; Partidos políticos brasileiros; Republic.com 2.0.

\section{Introdução}

Direito e Internet. Essa relação entre normas e novas tecnologias tem se tornado cada vez mais visível na atualidade, especialmente a partir dos anos sessenta, quando a Internet começou a ser arquitetada pelos norte-americanos. Quanto mais as tecnologias se aperfeiçoam e se tornam disponíveis para o público em geral (pessoas físicas, jurídicas, governos etc.), mais os operadores do direito se debruçam em estudá-las, com o objetivo de solucionar os conflitos que dessa relação emergem.

O ciberespaço propicia uma maior interação entre os diversos atores, fazendo com que a liberdade de expressão seja um direito amplamente difundido através da rede, assim como, mais recentemente, o direito de acesso à informação. Os governos, mas principalmente os 
partidos políticos, tem uma função primordial quanto à aplicação desses direitos em prol da comunicação e da democracia.

Inúmeros autores teorizam a respeito dessa temática em todo o mundo, mas um em específico e reconhecido internacionalmente, qual seja Cass Sunstein, aponta uma proposta singular diante da fragmentação de informações na rede mundial de computadores. Levando em consideração os argumentos do doutrinador, questiona-se: os principais partidos políticos brasileiros aderem à proposta de Sunstein externada na obra "Republic.com 2.0"?

Para responder a essa indagação, o método de abordagem utilizado foi o dedutivo, pois a pesquisa partiu de uma análise geral do direito à liberdade de expressão e de informação para, na sequência, expor a obra alicerce do presente trabalho. Em seguida, foi realizada a pesquisa propriamente dita com os sites dos partidos políticos brasileiros, no final do artigo.

Já os métodos de procedimento empregados foram o monográfico, em razão do estudo de uma obra específica e da principal proposta do autor. E o método estatístico, devido à investigação realizada ao final, com os partidos políticos no Brasil. Ademais, as técnicas de pesquisa aproveitadas foram a bibliográfica e a observação direta, sistemática e não participativa.

Diante desse aporte metodológico, o artigo foi dividido em dois capítulos e um subcapítulo. O primeiro capítulo tem como objetivo estudar o direito à liberdade de expressão e o direito de acesso à informação sob uma perspectiva constitucional. O segundo visa explorar a obra "Republic.com 2.0" e a principal proposta do autor Cass Sunstein. Finalmente, o subcapítulo desse tem por desígnio descobrir se os principais partidos políticos brasileiros aderem a tal sugestão.

\section{Liberdade de expressão e de informação na Internet: uma abordagem constitucional}

O século XXI, marcado pela emersão das Novas Tecnologias de Informação e Comunicação (TIC), especialmente da Internet, é o século da sociedade em rede global. As novas tecnologias permitem que os cidadãos se expressem cada vez mais através da rede, e que as informações estejam paulatinamente acessíveis para todos. $\mathrm{O}$ direito à liberdade de expressão e o direito de acesso à informação são reproduzidos, também, no ciberespaço.

A Internet, que nasceu no ano de 1969 nos Estados Unidos da América, só foi apresentada para as pessoas, as empresas e para a sociedade em geral no ano de 1995, ou seja, a exatos vinte e um anos (CASTELLS, 2007, p. 33). Para doutrinadores como Manuel Castells (2007, p. 25), 
A criação e desenvolvimento da Internet é uma extraordinária aventura humana. Mostra a capacidade das pessoas para transcender as regras institucionais, superar as barreiras democráticas e subverter os valores estabelecidos no processo de criação de um novo mundo. Serve também para reafirmar a ideia de que a cooperação e a liberdade de informação podem favorecer mais a inovação do que a concorrência e os direitos de propriedade.

Para Pierre Lévy (2001, p. 36), a Internet representa o fim das fronteiras, pois "Pela primeira vez a idéia de uma Terra sem fronteiras não aparece como a aplicação de um princípio abstrato ou como um devaneio utópico, mas como o prolongamento realista de uma tendência que cada um pode observar.”. O autor entende que os próximos séculos serão "planetários".

Liliana Minardi Paesani (2006), ao abordar questões relacionadas à Internet, Estado e Direito, afirma ser impossível saber sobre o futuro da democracia, e se no futuro haverá um aumento da desigualdade e marginalização, ou, ao contrário, uma democracia internacional, pautada pela garantia dos direitos humanos pelos Estados e poderes, especialmente após o surgimento das novas tecnologias. Para a referida autora, "A história, principalmente deste século, ensina que a democracia só se cria com o direito, e o direito só se cria com a razão." (PAESANI, 2006, p. 29).

Antes de adentrar nas questões atinentes à liberdade de expressão e ao direito de acesso à informação na Internet, faz-se importante referir que para alguns autores “informação" não é a mesma coisa que "comunicação". Dominique Wolton (2004, p. 24) entende que a informação, por si só, não é suficiente para gerar comunicação, pois, enquanto aquela é tão somente a mensagem transmitida, essa é a relação feita da mensagem recebida.

Além disso, Wolton (2004, p. 22) afirma que o excesso de informação é prejudicial, especialmente daquelas informações transmitidas por meio do ciberespaço, porque além de não simplificarem nada, complicam tudo. Scott Lash (2005, p. 259-260) denomina esse fenômeno de "desinformação", capaz de gerar impossibilidade de reflexão, irracionalizarão e falta de inteligência. Contudo, a liberdade de expressão e o direito de acesso à informação geram "informação", que pode ou não resultar em "comunicação". Muito irá depender da capacidade do receptor em processar a mensagem recebida.

Por outro lado, Adalberto Simão Filho (2007, p. 12) compreende que,

A referência da expressão Sociedade da Informação como um modelo de desenvolvimento socioeconômico em que a aquisição, armazenamento, processamento, valorização, transmissão, distribuição e disseminação de informação conducente à criação de conhecimento e à satisfação das necessidades dos cidadãos 
e das empresas desempenham um papel central na atividade econômica, na criação de riqueza, da definição da qualidade de vida dos cidadãos e das suas práticas culturais é por demais extensiva.

O autor não deixa de fazer referência à abundância de informação como algo que pode gerar não-informação ou impossibilidade de assimilação daquela. Mas propõe "Um retorno à ética clássica e aos princípios gerais do direito para a formação de um costume próprio para a Sociedade da Informação em cuja base encontram-se os preceitos da boa-fé e da responsabilidade social.” (SIMÃO FILHO, 2007, p. 26).

Com relação aos direitos fundamentais, Canotilho (2003, p. 393) os distingue dos direitos do homem, pois para o doutrinador esses são direitos válidos para todos os indivíduos em qualquer lugar e tempo. Já aqueles “[...] são os direitos do homem, jurídicoinstitucionalmente garantidos e limitados espacio-temporalmente. [...] os direitos fundamentais seriam os direitos objetivamente vigentes numa ordem jurídica concreta.”.

Quanto à teoria dos direitos fundamentais, faz-se importante referir as cinco gerações de direitos evidenciadas por Bonavides (2011), muito embora essa classificação possua variações a depender de cada autor. A primeira geração compreende os direitos de liberdade e pressupõe uma atuação negativa do Estado. A segunda, os direitos de igualdade, e requer uma atuação positiva do Estado. A terceira, os direitos de fraternidade, que focalizam o gênero humano. A quarta, os direitos de globalização política. E, por fim, a quinta geração de direitos, o direito à paz.

Pérez Luño (2012, p. 16-17), por sua vez, compreende serem os direitos de primeira geração aqueles que surgiram no Estado Liberal, de liberdades individuais. Os de segunda geração, aqueles que nasceram com o Estado Social, os direitos econômicos, sociais e culturais. Por fim, os direitos de terceira geração constituem a marca registrada do atual modelo político de Estado Costitucional de Direito. Quanto a essa última geração de direitos, o autor ensina que as expressões "novos direitos", "direitos da solidariedade", "direitos da era tecnológica", "direitos da sociedade global" e "direitos emergentes" não devem ser utilizadas, pois não há uma substituição de velhos por novos direitos.

Independentemente da classificação imposta, os direitos à liberdade de expressão e de informação estão previstos na Constituição Federal brasileira de 1988, como direitos fundamentais. Consta no artigo $5^{\circ}$, inciso IV, que "é livre a manifestação do pensamento, sendo vedado o anonimato". Mas também no inciso XIV do mesmo artigo, que afirma que "é assegurado a todos o acesso à informação e resguardado o sigilo da fonte, quando necessário ao exercício profissional” (BRASIL, 2016). 
Além disso, o artigo 220 da Carta Magna assevera que "A manifestação do pensamento, a criação, a expressão e a informação, sob qualquer forma, processo ou veículo não sofrerão qualquer restrição, observado o disposto nesta Constituição.” (BRASIL, 2016). Frente a isso, Branco (2015, p. 263) considera que “A liberdade de expressão é um dos mais relevantes e preciosos direitos fundamentais, correspondendo a uma das mais antigas reivindicações dos homens de todos os tempos.".

Para ele, a liberdade de expressão abrange a comunicação de pensamentos, de ideias, de informações e de expressões não verbais. Além disso, compreende também o direito de não se expressar, de se calar e de não se informar. Contudo, como a grande maior dos direitos fundamentais, o direito à liberdade de expressão possui limitações, com base no princípio da proporcionalidade e da dignidade da pessoa humana, que devem ser analisadas de acordo com o caso concreto (BRANCO, 2015, p. 263-270).

Como se está a tratar, no presente trabalho, sobre a incidência desses direitos na Internet, mister fazer menção à Lei 12.965/2014, também denominada Marco Civil da Internet. A novel legislação cita a liberdade de expressão em diversos dispositivos, como no artigo $2^{\circ} ; 3^{\circ}$, inciso I; $8^{\circ} ; 19$ e parágrafo $2^{\circ}$. O direito de acesso à informação é contemplado especificamente pelo artigo $4^{\circ}$, inciso II, da lei, que assegura "A disciplina do uso da internet no Brasil tem por objetivo a promoção do acesso à informação, ao conhecimento e à participação na vida cultural e na condução dos assuntos públicos.” (BRASIL, 2016).

Autores como Paulo Ferreira da Cunha (2007, p. 168-169), pontuam que a informação é recondutível à liberdade de expressão e à comunicação. Para ele, é a "Liberdade de Informação, uma forma de liberdade política e cidadã, ancorada no mais lato valor da Liberdade política (um dos três grandes valores políticos dos nossos tempos, a par da Justiça e da Igualdade).”. A Lei 12.527/2011, Lei de Acesso à Informação (LAI), foi promulgada para regular o direito de acesso à informação previsto na atual Constituição Federal (BRASIL, 2016).

O direito de acesso à informação perpassa pela ideia de governo aberto, seguido pelos princípios da transparência, colaboração e participação. A implementação dos governos abertos exige mudanças culturais, nos processos, na organização e nas formas de relação (CALDERÓN; LORENZO, 2010, p. 13-15). Para os autores Calderón e Lorenzo (2010, p. 16), tais modificações devem começar pelo funcionamento dos partidos políticos, já que: 
funcionamiento de los partidos políticos, que aún herederos de una tradición de control de la información y llenos de estructuras cerradas y poco flexibles, habrán de convertirse en espacios abiertos, dinámicos y permeables.

César Ramos Esteban (2010, p. 165-166) afirma que as novas tecnologias têm sido utilizadas pelos partidos políticos para se abrirem aos cidadãos, expondo suas propostas políticas e proporcionando espaços de interação. Nesse sentido, a Internet realiza uma aproximação entre os partidos e os cidadãos. Definitivamente, as ferramentas tecnológicas não devem ser utilizadas para a autopublicidade dos partidos políticos, mas sim para o trabalho e a aproximação dos indivíduos (ESTEBAN, 2010, p. 181).

Vários estudos já foram realizados a respeito da utilização das novas tecnologias pelos partidos brasileiros. Um deles, concretizado em 2015, revelou que “[...] a totalidade dos partidos brasileiros está presente on-line usando amplamente a internet e as principais mídias sociais "Web 2.0" para divulgar suas atividades e interagir com os cidadãos." (BRAGA; ROCHA; CARLOMAGNO, 2015, p. 51). Esta mesma pesquisa constatou que:

\footnotetext{
Podemos afirmar, portanto, que os partidos com mais recursos políticos usam com mais intensidade aquelas ferramentas que permitem uma comunicação "vertical" e "top down" entre as lideranças partidárias e outros atores políticos (formadores de opinião, mídia, potenciais financiadores de campanha, militantes e simpatizantes etc.), enquanto que os partidos menores e situados mais à esquerda do espectro partidário usam de maneira mais intensa aqueles recursos associados à mobilização e a uma maior interatividade com os cidadãos (BRAGA; ROCHA; CARLOMAGNO, 2015, p. 58).
}

Outros estudos analisaram as formas pelas quais os partidos políticos brasileiros se comunicam com seus eleitores no ciberespaço, com o propósito de identificar as principais estratégias discursivas, a informação política e a interação com os eleitores (RODRIGUES; BARROS; BERNARDES, 2014, p. 2).

O autor Pérez Luño (2012, p. 45-46) denomina "teledemocracia" o conjunto de teorias e fenômenos práticos relacionados à incidência das novas tecnologias na política. Para ele, três elementos devem ser observados, quais sejam: o elemento metodológico, relacionado às formas de manifestação no rádio, televisão, Internet, dentre outros. Também há o elemento objeto, o qual está relacionado com à participação política do cidadão, denominada pelo estudioso de "cibercidadania". Por fim, o elemento contexto e aplicação, os quais referem-se ao Estado de Direito e às projeções políticas, em prol de uma sociedade democrática. Assim, entende que a teledemocracia é o canal eficaz com que contam os Estados atualmente, pois dessa forma podem se expressar, ouvir, serem ouvidos e manifestar a vontade da soberania popular.

Barbarói, Santa Cruz do Sul, Edição Especial n.47, p.<303-317>, jan./jun. 2016 
No entanto, Eduardo Magrani (2014, p. 138), que busca afirmar a Internet como ferramenta de engajamento político-democrático, compreende que sem o incentivo ou estímulo necessários, os cidadãos não irão procurar, por exemplo, posições contrárias às suas próprias, no que tange à temas políticos. Diante disso, o doutrinador norte-americano Cass Sunstein, em uma de suas obras expõe uma proposta singular com relação ao uso da Internet, especialmente pelos partidos políticos, que será exposta na próxima seção deste trabalho. E, na sequência, será investigado se essa proposta está sendo aplicada pelos partidos no Brasil.

\section{Apresentação da obra "Republic.com 2.0" e da principal proposta do autor Cass Sunstein}

O livro "Republic.com 2.0", de autoria do norte-americano Cass Sunstein, foi publicado no ano de 2007 como uma resposta às críticas recebidas em relação a sua obra anterior, qual seja, "Republic.com". No livro o autor enfatiza questões atinentes à liberdade de expressão e à democracia, sendo os seus principais pontos expostos a partir de agora.

No primeiro capítulo, denominado "the daily me", ou jornal diário, termo criado por Nicholas Negroponte em 1995, Sunstein explica que os indivíduos tendem a procurar por informações que se assemelham aos seus próprios gostos e pontos de vista, realizando assim uma filtragem. Isso ocorre em razão de que, sobretudo nos tempos modernos, com destaque para a Internet, ninguém consegue ver, ouvir ou ler absolutamente tudo (SUNSTEIN, 2007, p. 1)

Com isso, muitos jornais, incluindo, por exemplo, o "Wall Street Journal", permitem que os seus leitores criem edições eletrônicas personalizadas, contendo exatamente o que os usuários querem e rechaçando o que eles não querem ler (SUNSTEIN, 2007, p. 3). Para o autor, o the daily me irá criar sérios problemas democráticos, pois para que haja um bom funcionamento do sistema de liberdade de expressão, dois requisitos precisam ser observados.

O primeiro diz respeito ao fato de que as pessoas devem ser expostas à materiais que elas não escolheram com antecedência. Isso porque, encontros não planejados e imprevistos são centrais para a democracia. O segundo é o de que, muitos ou a maioria dos cidadãos precisam ter ao seu alcance experiências comuns, já que não havendo o compartilhamento de experiências, uma sociedade heterogênea terá muito mais dificuldades para solucionar os problemas sociais e as pessoas acharão complicado compreender umas às outras (SUNSTEIN, 2007, p. 5-6). 
$\mathrm{Na}$ sequência, o autor destaca a ideia de "fórum público" e de "democracia deliberativa". Os fóruns públicos foram implementados nos Estados Unidos para que as ruas e parques pudessem ser mantidos abertos ao público, que desejasse realizar atividades expressivas, como discursos etc. Mas atualmente a Internet tem se mostrado mais relevante do que as ruas e parques, pois nada mais é do que uma "arena" onde a atividade expressiva acontece. Os intermediários, como jornais, revistas, emissoras de televisão e rádio, também são compreendidos como fóruns públicos importantes, já que expõe os indivíduos a uma ampla gama de assuntos e visões, ao mesmo tempo em que apresentam experiências compartilhadas (SUNSTEIN, 2007, p. 22).

Já a democracia deliberativa, que abarca o processo de participação pública na tomada de decisões, é o maior ideal geral constitucional de todos, pois envolve um relacionamento entre os governos e os cidadãos (SUNSTEIN, 2007, p. 32). Nesse sentido, Sunstein apresenta duas espécies de soberania, a "soberania do consumidor" e a "soberania política". A primeira envolve a ideia de mercados livres, já a segunda, a de nações livres. A soberania do consumidor significa a possibilidade de as pessoas escolherem exatamente o que elas desejam, sem quaisquer restrições. Já a soberania política envolve uma reflexão daquilo que os indivíduos querem, trocando informações e perspectivas diversas (SUNSTEIN, 2007, p. 38).

O fato é que, em um mundo onde as pessoas optam pela filtragem das informações, acabarão sendo criadas, nas palavras do autor, "câmaras de eco" e "casulos de informação". As consequências serão: 1) A fragmentação de informações e consequente polarização dos grupos, gerando extremismo, ódio, violência etc.; 2) O risco das escolhas dos indivíduos gerarem pouquíssima informação; 3) O pensamento de que liberdade significa satisfação das preferências privadas (SUNSTEIN, 2007, p. 44-45).

Uma das pesquisas trazidas na obra concluiu que, no ano 2000, de 60 sites políticos, somente 9 (ou 15\%) forneciam links de sites com visões opostas, enquanto 35 (ou 60\%) forneciam links de sites com a mesma opinião. No ano de 2006, de 50 sites políticos, somente 17 (ou 34\%) forneciam links de sites com visões opostas, enquanto 41 (ou 82\%) forneciam links de sites com a mesma opinião. Contudo, inerente destacar que quando os links de sites com visões opostas são fornecidos, tal atividade é realizada no intuito de demonstrar o quão perigosa, estúpida ou desprezível é a opinião do site adversário. Obviamente, para a democracia isso é indesejável (SUNSTEIN, 2007, p. 54-55).

No quarto capítulo do livro, "cola social e disseminação da informação", quer-se demonstrar que uma sociedade heterogênea se beneficia das experiências compartilhadas, 
muitas delas produzidas pela própria mídia. Essas experiências fornecem um tipo de "cola social", facilitando os esforços em solucionar os problemas compartilhados, encorajando as pessoas a verem umas às outras como cidadãs companheiras e, por vezes, ajudando a garantir uma capacidade de resposta para os problemas e as necessidades (SUNSTEIN, 2007, p. 97).

Em seguida é teorizado sobre os "blogs", onde cabe destacar a existência de 55 milhões desses a época em que a presente obra foi escrita. Ademais, importante registrar que 44 mil novos blogs são criados todos os dias, um novo blog a cada 2,2 segundos. Os blogs políticos, embora não sejam maioria, são abundantes, e parecem estar influenciando as crenças e julgamentos dos indivíduos. Embora a blogosfera seja um lugar de deliberação, há que se tomar cuidado em separar as informações falsas dos fatos verdadeiros (SUNSTEIN, 2007, p. 138).

Nesse sentido, existem grandes evidências de que muitos blogueiros estejam relacionando-se com outros blogueiros com as mesmas opiniões, e que quando se relacionam àqueles com opiniões diversas é para ridicularizá-los ou desprezá-los. Outro estudo, que analisou 1.400 blogs, constatou que 91\% deles proporcionam links para sites com os mesmos pontos de vista. O problema é que liberais, lendo blogs liberais, acabarão se tornando mais liberais, ao passo que conservadores, lendo blogs conservadores, acabarão se tornando mais conservadores. Por outro lado, a blogosfera aumenta o leque de informações e perspectivas disponíveis, sendo essa uma excelente virtude, sobretudo para as pessoas curiosas e com a mente aberta (SUNSTEIN, 2007, p. 150).

O capítulo sete, que trata sobre regulação, parte do pressuposto de que a oposição à regulação governamental na Internet é incoerente, pois a questão não é se devemos ter regulação, mas que tipo de regulação teremos. O bom funcionamento de um sistema de liberdade de expressão depende de direitos adequados. Nesse sentido cita-se como exemplo, o ciberterrorismo, onde não faria sentido os indivíduos se protegerem sozinhos, sem a interferência governamental (SUNSTEIN, 2007, p. 164).

Quando Sunstein passa a falar especificamente do princípio da liberdade de expressão, ele expõe um caso para comprovar que esse direito não é absoluto, especialmente na rede mundial de computadores. Foi criado um site denominado "The Nuremberg Files". Ele continha uma longa lista de pessoas que realizavam aborto e seus cúmplices. A lista incluía os nomes, endereços residenciais e as placas dos carros de vários médicos que realizaram abortos, e também incluía os nomes de seus cônjuges e filhos. Cumpre registrar que três desses médicos foram mortos. Ainda, no site haviam fotos dos mesmos com a escrita "procurado" abaixo da imagem de suas faces, reportando-se ao conhecido estilo "velho 
oeste”. Um grupo de médicos processou os responsáveis pela página, obtendo 100 milhões de dólares pelos danos, cujo valor foi reduzido substancialmente em sede de recurso (SUNSTEIN, 2007, p. 165-166).

Finalmente, como proposta para a Internet, o autor afirma que os fornecedores de material com um determinado ponto de vista, devem também fornecer links para sites com pontos de vista opostos. O ícone poderia tão somente apresentar um sinal, informando da existência de opiniões contrárias, as quais podem ser igualmente consultadas. Se grande parte dos sites fornecesse essa informação, o problema da fragmentação seria, ao menos, reduzido (SUNSTEIN, 2007, p. 208).

Em uma República livre, de acordo com o doutrinador, os cidadãos aspiram por um sistema que forneça uma ampla gama de experiências - com pessoas, tópicos e ideias - que eles não haviam especificamente selecionado antes (SUNSTEIN, 2007, p. 223).

\section{Análise da aplicação da proposta nos sites dos principais partidos políticos brasileiros}

Primeiramente, insta salientar que nenhuma pesquisa como essa foi encontrada no período da averiguação, maio de 2016. O objetivo da investigação é descobrir se os principais partidos políticos brasileiros oferecem links, em seus sites oficiais, que direcionem os cidadãos para outras páginas da web, especificamente para sites de outros partidos com visões opostas, como sugere Cass Sunstein.

De acordo com o Tribunal Superior Eleitoral, existem trinta e cinco partidos políticos registrados no Brasil até então. São eles: 1) PMDB - Partido do Movimento Democrático Brasileiro; 2) PTB - Partido Trabalhista Brasileiro; 3) PDT - Partido Democrático Trabalhista; 4) PT - Partido dos Trabalhadores; 5) DEM - Democratas; 6) PCdoB - Partido Comunista do Brasil; 7) PSB - Partido Socialista Brasileiro; 8) PSDB - Partido da Social Democracia Brasileira; 9) PTC - Partido Trabalhista Cristão; 10) PSC - Partido Social Cristão; 11) PMN - Partido da Mobilização Nacional; 12) PRP - Partido Republicano Progressista; 13) PPS - Partido Popular Socialista; 14) PV - Partido Verde; 15) PTdoB Partido Trabalhista do Brasil; 16) PP - Partido Progressista; 17) PSTU - Partido Socialista dos Trabalhadores Unificado; 18) PCB - Partido Comunista Brasileiro; 19) PRTB - Partido Renovador Trabalhista Brasileiro; 20) PHS - Partido Humanista da Solidariedade; 21) PSDC - Partido Social Democrata Cristão; 22) PCO - Partido da Causa Operária ; 23) PTN Partido Trabalhista Nacional; 24) PSL - Partido Social Liberal; 25) PRB - Partido Republicano Brasileiro; 26) PSOL - Partido Socialismo e Liberdade; 27) PR - Partido da 
República; 28) PSD - Partido Social Democrático; 29) PPL - Partido Pátria Livre; 30) PEN Partido Ecológico Nacional; 31) PROS - Partido Republicano da Ordem Social; 32) SD Solidariedade; 33) NOVO - Partido Novo; 34) REDE - Rede Sustentabilidade; 35) PMB Partido da Mulher Brasileira (BRASIL, 2016).

Desses, foram selecionados os principais, aqui entendidos como aqueles que possuem o maior número de eleitores, acima de um milhão, quais sejam: 1) PMDB - 2.398.324; 2) PT - 1.589.260; 3) PSDB - 1.443.769; 4) PP - 1.436.720; 5) PDT - 1.248.632; 6) PTB 1.191.746; 7) DEM - 1.095.712 (BRASIL, 2016). Os sites dos demais partidos não foram investigados na presente pesquisa.

Os resultados do estudo, realizado na segunda quinzena do mês de maio de 2016, foram no seguinte sentido: 1) Dos sete partidos políticos acima citados, um estava com o site oficial indisponível, qual seja o PTB, sendo que ao digitar o endereço eletrônico do partido no buscador na Internet, a mensagem “Aguarde, em breve o novo site do PTB” aparecera; 2) Dos seis sites dos partidos políticos restantes, nenhum disponibiliza links para sites de outros partidos, quanto muito para sites com pontos de vista ou posicionamentos opostos; 3) O PDT, no entanto, fornece "tags" direcionadas para notícias relacionadas ao PMDB e PNBL; 4) O PSDB e o DEM, por sua vez, apresentam links em destaque nas suas homepages contendo veementes críticas ao PT. A página inicial do PSBD contém um link denominado "Herança maldita: clique e veja o resultado de 13 anos de PT”. O DEM contém um vídeo de dez minutos em destaque na sua página inicial, cujo conteúdo são críticas e insultos ao PT.

Com isso, percebe-se que os principais partidos políticos brasileiros não aderem à proposta de Cass Sunstein, muito pelo contrário, estão distantes da sua concretização. A fragmentação das informações é visível, especialmente diante da crise política que vive o Brasil no presente momento. Além disso, constata-se a adoção da política do escândalo, muito bem teorizada por Castells (2013, p. 327), que afirma ser essa “[...] uma forma de luta pelo poder mais enraizada e típica que o desenvolvimento ordenado da competência política de acordo com as leis do estado.”.

Para o doutrinador, a comunicação atrelada à Internet contribui muito para a política do escândalo, de duas formas. A primeira diz respeito às múltiplas fontes de informação, reduzindo a capacidade de filtragem dos meios tradicionais, como jornal, rádio e televisão. E a segunda, refere-se ao fato de qualquer notícia, em qualquer formato e de qualquer procedência, ter uma imediata e ampla difusão no ciberespaço (CASTELLS, 2013, p. 334).

Com isso, o autor conclui que os efeitos dessa política nos resultados políticos são incertos, pois tudo depende do contexto cultural e institucional, da relação entre o escândalo e 
o político, do clima do recebimento de tais notícias pelo país, e da intensidade do cansaço dos indivíduos após as reiterações constantes do escândalo pelos meios de comunicação (CASTELLS, 2013, p. 341). Contudo, não é essa a proposta de Sunstein, que defende a troca de pontos de vista e opiniões, para a formação de convicções próprias, e não a política do escândalo, que é, a nosso ver, antidemocrática.

\section{Conclusão}

Frente a todo o exposto, conclui-se que o direito à liberdade de expressão e de informação passam a ter maior enfoque com o advento da Internet, e que os governos e os partidos políticos são, também, responsáveis por isso. Muitos autores tratam a respeito desse assunto, não somente por relacionar-se aos direitos fundamentais previstos na Constituição Federal brasileira, mas por gerar polêmicas quanto ao excesso de informação, a falta de comunicação, a fragmentação de informação etc.

O norte-americano Cass Sunstein, em sua obra "Republic.com 2.0", apresenta uma proposta que visa ao menos reduzir a fragmentação das informações no ciberespaço. O autor sugere que os sites, principalmente os de partidos políticos, disponibilizem links em suas homepages que direcionem o leitor a outros sites com pontos de vista ou posicionamentos contrários, em prol da democracia.

Essa proposta, conforme pesquisas divulgadas no livro pelo doutrinador, não foi implementada nos Estados Unidos de forma consistente, pois a maioria dos sites, quando proporcionam links para outros sites divergentes, o fazem para criticar e tentar demonstrar o quão prejudicial são as ideias opostas. Diante disso, foi realizada análise dos sites dos principais partidos políticos brasileiros com o intuito de desvendar se estes aderem à proposta.

Verificou-se que nenhum dos principais partidos, quais sejam PMDB, PT, PSDB, PP, PDT, PTB e DEM, oferecem esse tipo de link em suas homepages na Internet. Inclusive dois deles, PSDB e DEM, realizam justamente o contrário, pois disseminam fortes críticas ao PT. Isso pode ser denominado de "política do escândalo" que se opõe ao que Sunstein defende, pois antidemocrática.

Entende-se que a proposta do autor é válida e muito importante em termos de promoção da democracia, especialmente por dizer respeito à atuação dos partidos políticos na Internet. Ocorre que, a grande maioria dos sites, seja nos Estados Unidos, seja no Brasil, não a aplicam. Devido a isso, faz-se necessário refletir sobre formas de implementação efetiva dessa proposta, que não obrigue, mas que conscientize, ou até mesmo faça nascer uma cultura 
em que pontos de vista e posicionamentos opostos possam ser encontrados no ambiente virtual, de forma a evitar a fragmentação de informações.

\title{
FREEDOM OF SPEECH AND INFORMATION: ANALYSIS OF THE WEBSITES OF MAJOR BRAZILIAN POLITICAL PARTIES FROM THE CASS SUNSTEIN PROPOSAL IN "REPUBLIC.COM 2.0" WORK
}

\begin{abstract}
The objective of this work is to investigate whether the major Brazilian political parties adhere to the Cass Sunstein proposal in "Republic.com 2.0" work. Therefore, it was used the deductive method of approach, and the research permeated the study of freedom of speech and information by such work and, finally, the study of the websites of political parties in Brazil. The method of procedure employed was the monographic, in order to expose the author's work and reflect on its main purpose. In addition to the techniques of literature and direct observation, systematic and non-participatory. It was concluded that Brazilian parties does not adhere to the Sunstein proposal, with respect to providing links to other supporters sites with views or opposite positions on their homepages, and, instead, adopt the "scandal politics", something undemocratic.
\end{abstract}

Key words: Cass Sunstein; Access to information right; Freedom of speech; Brazilian political parties; Republic.com 2.0.

\section{Referências}

BONAVIDES, Paulo. Curso de direito constitucional. 26. ed. São Paulo: Malheiros Editores Ltda., 2011.

BRAGA, Sérgio; ROCHA, Leonardo Caetano; CARLOMAGNO, Márcio Cunha. A internet e os partidos políticos brasileiros. In: THEMOTEO, Reinaldo J.. Caderno Adenauer XVI, n'3: internet e sociedade. Rio de Janeiro: Fundação Konrad Adenauer, 2015. Disponível em: <http://www.kas.de/wf/doc/16515-1442-5-30.pdf>. Acesso em: 28 mai. 2016.

BRANCO, Paulo Gustavo Gonet. Direitos fundamentais em espécie. In: MENDES, Gilmar Ferreira; BRANCO, Paulo Gustavo Gonet. Curso de direito constitucional. 10. ed. São Paulo: Saraiva, 2015.

BRASIL. Constituição da República Federativa do Brasil. Publicada no Diário Oficial da União n. 191-A, de 5-10-1988. VadeMecum OAB e concursos. 8. ed. São Paulo: Saraiva, 2016.

Lei de Acesso à Informação. Lei n. 12.527, de 18 de novembro de 2011. Publicada no Diário Oficial da União, de 18-11-2011. VadeMecum OAB e concursos. 8. ed. São Paulo: Saraiva, 2016. 
Marco Civil da Internet. Lei n. 12.965, de 23 de abril de 2014. Publicada no Diário Oficial da União, de 24-4-2014. VadeMecum OAB e concursos. 8. ed. São Paulo: Saraiva, 2016.

Tribunal Superior Eleitoral: o tribunal da democracia. Estatísticas de eleitorado Filiados, 2016. Disponível em: <http://www.tse.jus.br/eleitor/estatisticas-deeleitorado/filiados>. Acesso em: 27 mai. 2016.

Partidos políticos registrados no TSE, 2016. Disponível em:

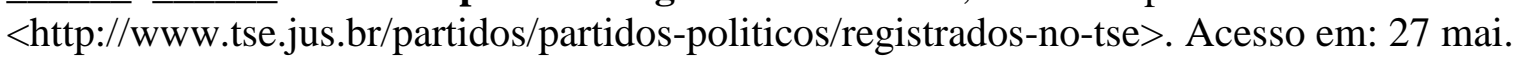
2016.

CALDERÓN, César; LORENZO, Sebastián. Open government: gobierno abierto. Algón Editores, 2010.

CANOTILHO, José Joaquim Gomes. Direito constitucional e teoria da constituição. 7. ed. Coimbra: Edições Almedina, 2003.

CASTELLS, Manuel. A galáxia internet: reflexões sobre internet, negócios e sociedade. Tradução de Rita Espanha. 2. ed. Lisboa: Fundação Calouste Gulbenkian, 2007.

O poder da comunicação. Tradução de Rita Espanha. Lisboa: Fundação Calouste Gulbenkian, 2013.

CUNHA, Paulo Ferreira da. Direito à informação ou deveres de protecção informativa do Estado? In: SARLET, Ingo Wolfgang (org.). Direitos fundamentais, informática e comunicação: algumas aproximações. Porto Alegre: Livraria do Advogado Ed., 2007.

ESTEBAN, César Ramos. La abertura a la sociedad: una necesidad. In: CALDERÓN, César; LORENZO, Sebastián. Open government: gobierno abierto. Algón Editores, 2010.

LASH, Scott. Crítica de la información. Traducción de Horacio Pons. Buenos Aires: Amorrortu, 2005.

LÉVY, Pierre. A conexão planetária: o mercado, o ciberespaço, a consciência. Tradução de Maria Lúcia Homem e Ronaldo Entler. São Paulo: Ed. 34, 2001.

MAGRANI, Eduardo. Democracia conectada: a internet como ferramenta de engajamento político-democrático. Curitiba: Juruá, 2014.

PAESANI, Liliana Minardi. Direito e internet: liberdade de informação, privacidade e responsabilidade civil. 3. ed. São Paulo: Atlas, 2006.

PÉREZ-LUÑO, Antonio Enrique. Los derechos humanos enla sociedad tecnológica: Editora Universitas: Madrid, 2012.

RODRIGUES, Malena Rehbein; BARROS, Antonio Teixeira de; BERNARDES, Cristiane Brum. Palanques virtuais: o uso de websites pelos partidos políticos brasileiros. $\mathbf{3 8}^{\mathbf{0}}$ Encontro Anual da ANPOCS. Caxambu - MG. Outubro, 2014. Disponível em: 
$<$ http://www.anpocs.org/portal/index.php?option=com_docman\&task=doc_details\&gid=8858 \&Itemid=456> Acesso em: 28 mai. 2016.

SIMÃO FILHO, Adalberto. Sociedade da informação e seu lineamento jurídico. In:

PAESANI, Liliana Minardi. O direito na sociedade da informação. São Paulo: Atlas, 2007.

SUNSTEIN, Cass R.. Republic.com 2.0. Princeton University Press: New Jersey, 2007.

TREIN, Aline; SOUZA, Lucas Silva de; NASCIMENTO, Valéria Ribas do. Resenha crítica do livro "Republic.com 2.0", de Cass Sunstein: das "câmaras de eco" à "cola social". Revista Direitos Emergentes na Sociedade Global. Santa Maria - RS, 2012.

WOLTON, Dominique. La otra mundialización: los desafíos de la cohabitación cultural global. Traducción Irene Agoff. Barcelona: Editorial Gedisa, S.A., 2004.

\section{Sobre os autores:}

Rafaela Bolson Dalla Favera é Mestranda do Programa de Pós-Graduação em Direito da Universidade Federal de Santa Maria (UFSM), Bacharel em Direito pelo Centro Universitário Franciscano (UNIFRA) e pesquisadora do Núcleo de Direito Informacional (NUDI) da Universidade Federal de Santa Maria (UFSM). E-mail: rafaeladallafavera@ hotmail.com

Patrícia dos Reis é Mestranda do Programa de Pós-Graduação em Direito da Universidade Federal de Santa Maria (UFSM), Bacharel em Direito pela Faculdade Metodista de Santa Maria (FAMES) e pesquisadora do Centro de Estudos e Pesquisa em Direito e Internet (CEPEDI) da Universidade Federal de Santa Maria (UFSM). E-mail: patriciareista17@yahoo.com.br 